ISSN 2466-2232

Online ISSN 2466-2100

\title{
Effect of Burn-off Length on the Properties of Friction Welded Dissimilar Steel Bars
}

\author{
Muralimohan Cheepu*, and Woo Seong Che*, \\ *Department of Mechatronics Engineering, Kyungsung University, Busan, 48434, Korea \\ †Corresponding author : wsche@ks.ac.kr \\ (Received October 24, 2018 ; Revised November 13, 2018 ; Accepted January 3, 2019)
}

\begin{abstract}
Friction welding is one of the solid state welding process and it is very popular method to join cylindrical components of similar and dissimilar metals. It is most economical and high productive method for various applications of aerospace, automotive and chemical industries. The joining of austenitic stainless steels using fusion welding methods associated with many problems such as solidification cracks and grain growth. To alleviate these problems, friction welding method has been used for joining of austenitic stainless steel to carbon steel. The process parameters such as burn-off length is one of the significant welding condition to govern the heat generation and coefficient of friction during welding. Burn-off length of $1 \mathrm{~mm}$ to $6 \mathrm{~mm}$ was selected to investigate its effect on mechanical properties and weld interface characteristics. An optical, scanning electron microscope and electron backscattered diffraction analyses were used to characterize the weld interface properties. The mechanical properties of the joints were evaluated by using hardness, tensile and fatigue tests. It is observed that, strength of the joints were increased with increasing of burn-off length up to optimum value of $4 \mathrm{~mm}$ and starts to decrease on further increasing of burn-off length.
\end{abstract}

Key Words : Friction welding, Mechanical properties, Microstructure, Stainless steel, Carbon steel, Burn-off length

\section{Introduction}

Friction welding is a solid state welding process which is being used widely in recent years due to its prominent gains and advantages on low production time, low heat input, and ease of manufacture and, the selection of welding conditions compared to other welding methods. The joining of ferrous and nonferrous materials either in similar or dissimilar combinations, which are not able to join by using fusion welding methods, can be successfully joined by friction welding method ${ }^{1,2)}$. In this process, two materials were joined by the frictional heat generated by relative motion of the rubbing of two contact surfaces under axial force. The required heat for producing the joints mostly depending on the proper selection of welding conditions. In this process, the important welding conditions of friction pressure, upset pressure and burn-off length need to be decide based on the type of substrates were selected for joining. However, the prior experience is needed to understand the range of welding conditions. The quality of the joints were mainly depending on proper selection of the friction welding parameters.

Many manufacturing industries are interested to weld dissimilar combinations of austenitic stainless steels (SS) to carbon steels (CS) due to their widespread applications, especially in the power plants and ballistic armour tanks, where the inner walls were made with soft materials and are covered by hard and tough materials $^{3-5)}$. The mechanical and corrosion properties of dissimilar friction welding combinations of advanced materials are still needed an immense number of research and development for specific applications. However, the welding of dissimilar materials encountered with various metallurgical drawbacks, which are detrimental to the weld strength of fusion welded joints ${ }^{6-9)}$. The friction welding of dissimilar material combinations were studied extensively on experimental and theoretical analysis. Moreover, the effect of friction welding pa- 
rameters on joint properties of various steels are investigated in the previous literature studies. Among them, some studies were reported that for producing of high strength welds between high speed steel (R6M5) and carbon steel (SAE 1045), the optimum friction welding conditions were identified experimentally ${ }^{10)}$. Sahin ${ }^{11)}$ has been investigated that the friction welded joint interface properties of similar combination of austenitic stainless steel (AISI 304SS). The tensile strength of welds were gradually increased with increasing of friction time and started to reduce after reaching its optimal value of 9 seconds. Meshram et $\mathrm{al}^{12)}$, were reported that the effect of burn-off length on various dissimilar combinations. It was observed that, central region of the weld interface was effected with the formation of intermixing layers. They also observed that, the range of burn-off length between $3 \mathrm{~mm}$ and $5 \mathrm{~mm}$ was revealed a good amount of ductility for the friction welded joints. The fractured surfaces of the welds produced at below $3 \mathrm{~mm}$ of burn-off length was revealed an extent of faceted fracture which was different from the ductile nature of fracture. Moreover, the effect of friction time which is relevant to the burn-off length was studied by various researchers on austenitic stainless steel to titanium alloys and reported that, most of the burrs were formed on titanium side compared to the stainless steel $^{13-15)}$. Whereas, the friction welding between two hard materials of steel to other type of steels was revealed a different characteristics under the effect of burn-off length which plays a vital role on the joint interface. Li et $\mathrm{al}^{16)}$ have been investigated the influence of friction time, axial shortening and weld shape for the SAE 1045 steel. It was observed that, the amount of burn-off length was depending on the combined effect of friction time and friction pressure, which were considered as significant parameters for achieving highest tensile strength. Consequently, some of the studies were reported that the influence of friction pressure and friction time on strength of the welds between medium carbon steel and high carbon steel. It was reported that the fracture occurred at the base metal when the friction time varied from 0.7 to 3 seconds at the two different friction pressures of $30 \mathrm{MPa}$ and $90 \mathrm{MPa}^{17)}$.

Friction welding of hard materials such as high tensile and wear resistant steels to the austenitic stainless steels, the plasticity formation is one of the issue. Therefore, the amount of formation of weld flash during welding is quite different from the friction welding of ordinary steels. The most commonly used dissimilar material combinations of AISI 4140 high tensile steel to AISI 304 austenitic stainless steel material properties have large difference in their ductility. The friction welding of these combinations were revealed that the required burn-off length values are very high and were started from $5 \mathrm{~mm}$ to $12 \mathrm{~mm}$. Therefore, to obtain the required weld flash with sufficient intermixing regions at joint interface were determined by the proper selection of range of burn-off length values. The resultant of the chemical analysis of the welds which are made at burn-off length of $5 \mathrm{~mm}$ and $12 \mathrm{~mm}$ were revealed a large amount of difference in $\mathrm{Ni}$ and $\mathrm{Cr}$ contents, which are caused due to the improper mixing regions ${ }^{18)}$. Lee ${ }^{19)}$ et al, have been investigated the effect of friction time on tensile strength of the joints and they reported that small amount of friction time were enough to achieve the highest tensile strength for low and medium carbon steel combinations of SKH51 to SM45C steels.

Paventhan et $\mathrm{al}^{20)}$ have been investigated that the optimization of welding conditions for the friction welding combinations of austenitic stainless steel to carbon steels with varying the friction time and friction pressure parameters. They were concluded that friction time (burn-off length) have most eminent effect on strength of the joints. Whereas, these combination of dissimilar steels with austenitic stainless steels have negative metallurgical reactions with the formation of delta ferrite and chromium carbide precipitates along the grain boundaries, thus the sensitization effects can be found for the welds produced by fusion welding methods ${ }^{3}$. However, these metallurgical issues are anticipating to minimize by using friction welding method. Moreover, to the best of this author's knowledge, there is no studies reported on the formation of secondary phases which are detrimental to the strength of friction welds between stainless steel to other type of steels ${ }^{21-23)}$. In the present study, friction welding of austenitic stainless steel to medium carbon steel were joined to achieve the highest tensile strength. The crucial applications of this dissimilar combination are involved in automotive parts such as wheel spindle, engine valves and drive extension rods. The accuracy in their total length is very important for utilising these parts in the end components. In order to obtain the required dimensions with sufficient strength for the parts, the proper selection of welding parameters are highly required. Hence, the influence of burn-off length has been investigated on the mechanical and metallurgical properties of the joints. The formation of intermixing layers and grain structure was characterized at joint interface. The fatigue strength of the joints is also evaluated and investigated the fracture morphologies of the failure surfaces.

\section{Materials and Methods}

In this study, austenitic stainless steel (AISI316L) and 
Table 1 Chemical composition (wt.\%) of the materials used in the present study

\begin{tabular}{|c|c|c|c|c|c|c|c|c|c|c|c|}
\hline Materials & $\mathrm{C}$ & $\mathrm{Si}$ & $\mathrm{Mn}$ & $\mathrm{Cu}$ & $\mathrm{P}$ & $\mathrm{S}$ & $\mathrm{Ni}$ & $\mathrm{Cr}$ & $\mathrm{Mo}$ & $\mathrm{N}$ & $\mathrm{Fe}$ \\
\hline SAE1045 & 0.45 & 0.28 & 0.70 & 0.12 & 0.01 & 0.01 & 0.04 & 0.10 & - & - & balance \\
\hline AISI316L & 0.03 & 0.85 & 1.6 & - & 0.045 & 0.03 & 13.9 & 17.68 & 3.4 & 0.1 & balance \\
\hline
\end{tabular}

Table 2 Mechanical properties of the materials

\begin{tabular}{|c|c|c|c|c|}
\hline Materials & Tensile strength (MPa) & Yield strength (MPa) & Elongation (\%) & Hardness (Hv) \\
\hline AISI316L & 715 & 592 & 39 & 219 \\
\hline SAE1045 & 724 & 619 & 41.5 & 205 \\
\hline
\end{tabular}

carbon steel (SAE1045) materials with the dimensions of $16 \mathrm{~mm}$ in diameter and $100 \mathrm{~mm}$ in length rods were used. The chemical composition of the substrates are provided in Table 1. The mechanical properties of the materials are tested at room temperature, and are given in Table 2. The faying surfaces of the substrates were machined and followed by polished with 1200 grit emery paper before performing the welds, in order to obtain an accuracy in the weld strength. The weld surfaces were polished to get the required surface roughness, which has more significant effect on the enhancing of joints strength. Prior to friction welding, all the samples were thoroughly cleaned with alcohol to remove the oil, grease and dirt, etc. A continuous drive friction welding machine with a capacity of $200 \mathrm{kN}$ of ETA make was used to make the friction welds. The process parameters have more significant effect in the friction welding process to obtain the sound welds between dissimilar materials. The process parameters such as burn-off length, friction pressure, upset force, upset time, and spindle speed have direct relation to the formation of joint and on its strength. To achieve the higher tensile strength of the welds, a new set of welding parameters were intended after the several experimental trails of the welds with varying the burn-off length from $1 \mathrm{~mm}$ to $6 \mathrm{~mm}$, and other parameters were kept as constant with a friction pressure of $110 \mathrm{MPa}$, upset pressure of $240 \mathrm{MPa}$, upset time of $5 \mathrm{sec}$ and the rotational speed of $1500 \mathrm{rpm}$.

Friction welded joints were cut into cross sections for metallographic sample preparations. To characterise the microstructural features, samples were polished as per the standard metallographic procedures. To evaluate the mechanical properties of the joints, tensile and fatigue test samples were prepared as per the ASTM E8 and ASTM E466 standards respectively, and are depicted in Fig. 1. The tensile tests were performed on the universal testing machine of TFUC-400 model. The nano-indentation tester (Hysitron, TI950 TriboIndenter) was used to determine the hardness of the joints. The joint interface microstructural observations were characterised by opti-

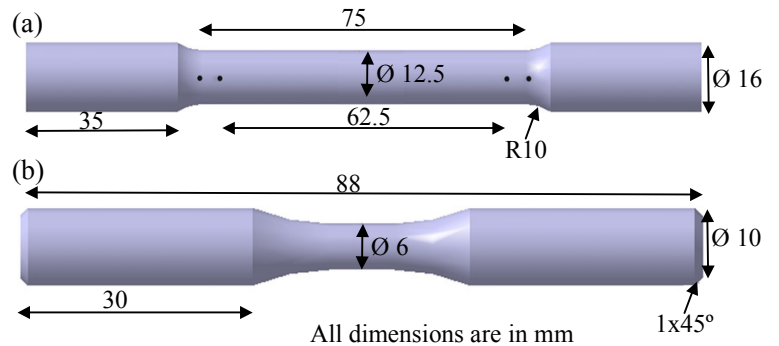

Fig. 1 Dimensions of the test specimens used in this study as per the ASTM standards for (a) tensile and (b) fatigue test

cal microscope, scanning electron microscope (SEM) and electron backscattered diffraction analysis (EBSD). To reveal the microstructural features of the welds, polished surfaces were etched with $2 \%$ nitol solution on the carbon steel side and an aqua-regia solution on stainless steel side were used.

\section{Results and Discussion}

\subsection{Macro and microstructural analysis}

The macrostructure of the friction welded joint which was produced between carbon steel (CS) and stainless steel (SS), is illustrated in Fig. 2. The appearance of the weld cross section from CS side to SS side were revealed a large difference in the formation of burrs of the weld flash, which is extruded and plastically deformed from the rubbing surfaces during welding. The difference in this weld flash is one of the typical characteristic of the dissimilar friction welds ${ }^{2,24-27)}$. The amount of plastic deformation on material flow is observed to be more on the CS side compared to the SS side, it was happened due to the low tensile strength of the carbon steel at elevated temperatures is around $132 \mathrm{MPa}$ at 600 ${ }^{\circ} \mathrm{C}{ }^{27}$. The material properties at high temperatures are different for CS and SS, are presented in Fig. 3. The difference in decreasing of young's modulus of both the 


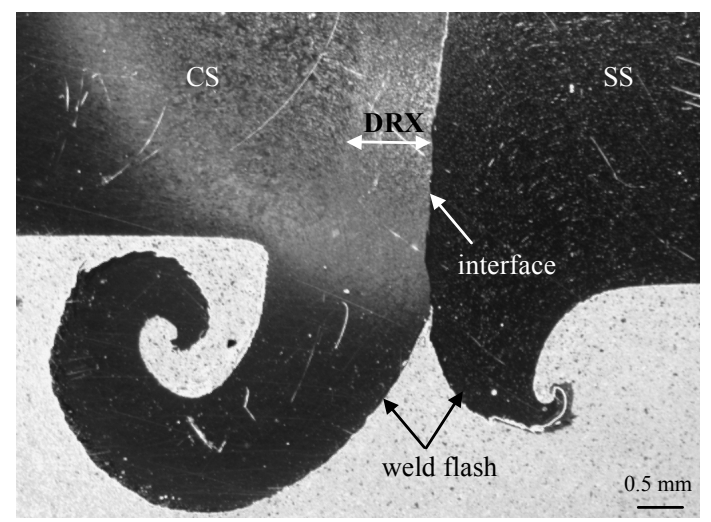

Fig. 2 Macrostructure of the friction welded joints shows the formation of weld flash of carbon steel (CS) and stainless steel (SS) and the width of dynamic recrystallization zone on CS side

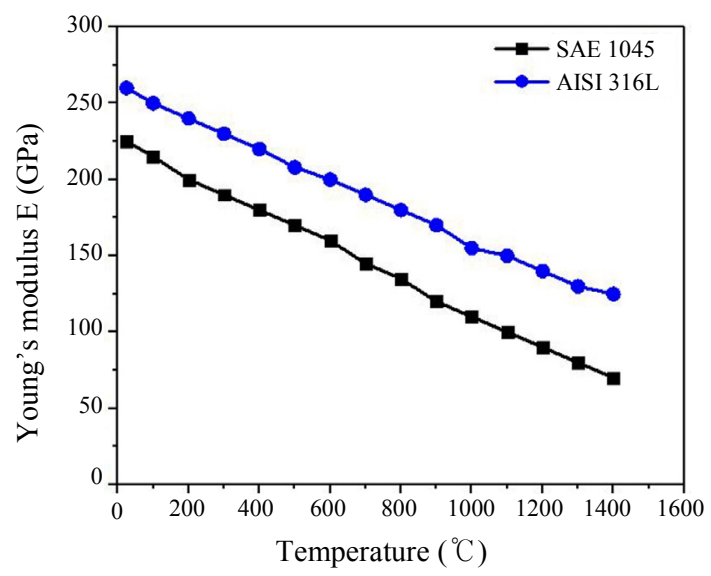

Fig. 3 Young's modulus of the materials at high temperatures

steels at high temperatures lead to the difference in formation of weld flash. The microstructure of CS/SS joint interface shows a region of approximately $800 \mu \mathrm{m}$ comprising of fine dynamic recrystallized zone (DRX) grains on the CS side adjacent to the weld interface, is shown in Fig. 4. Whereas, grain refinement on SS side is quite different from the CS side and its width is observed about $100 \mu \mathrm{m}$, due to its high resistance to deformation at elevated temperatures (as shown in Fig. 3). Fig. 4 shows the optical micrograph of joint interface with the regions of base metal (BM), thermo mechanically affected zone (TMAZ) and DRX, on CS and SS sides. The dark etched region up to the marked line from weld centre on CS side is indicated as a grain refinement due to dynamic recrystallization effect and the plastically deformed grains in TMAZ region (approximately $600 \mu \mathrm{m})$ are clearly indicated in Fig. 4. In the same Fig, right side to the weld centre the marked region on SS side shows the width of DRX zone (approximately $100 \mu \mathrm{m}$ ) and the presence of TMAZ is very small and its width is identified about $40 \mu \mathrm{m}$. The reason for presence of DRX regions and its characteristics are mainly owing to the heavy plastic deformation during friction welding can be occur at elevated temperatures close to the melting point of the substrates. Under this deformation, large number of dislocations have been induced in the material. Once the density of these dislocations changes, they have a tendency to form sub grain structures. Therefore, these low angle grains deform to make high angle grains, which is formed as region of very fine equi-axed grains compared to the base metals and other zones, is known as DRX region ${ }^{28)}$. In order to differentiate the DRX region with the unaffected microstructure regions of the base metal microstructures of CS and SS are illustrated in Fig. 5. Moreover, it is observed that the width of DRX zone is gradually increasing with the increases of burn-off length. This is due to the raise of heat generation with the increasing rate of material burning rate and heat dissipation towards the base metal from the centre of weld interface. The further analysis of joint interface were characterized with the optical and SEM microstructures, are exhibited in Fig. 6. Fig. 6(a) shows the optical image with the presence of fine grains (DRX) on the carbon steel side and joint interface with the intermixing region of both substrates. Whereas, there is no large deformed regions and fine grains were observed on stainless steel side due to its high tensile strengths at elevated temperatures over the carbon steel. As mentioned earlier, there is a small amount of DRX and TMAZ regions exists on the SS side, which can be seen clearly from the Fig. 4 . The higher magnification view of the SEM image of mixed region at interface is shown in Fig. 6(b), which is consisting of several sublayers. The interface between the CS matrix and mixed region represents as smooth and planar in nature, whereas the interface of intermixing

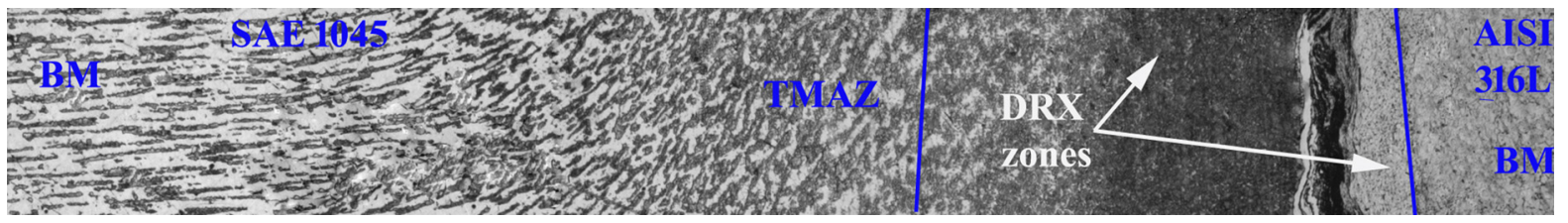

Fig. 4 Microstructure of the friction welded joint showing the different zones of base metal, TMAZ, DRX and weld interface 

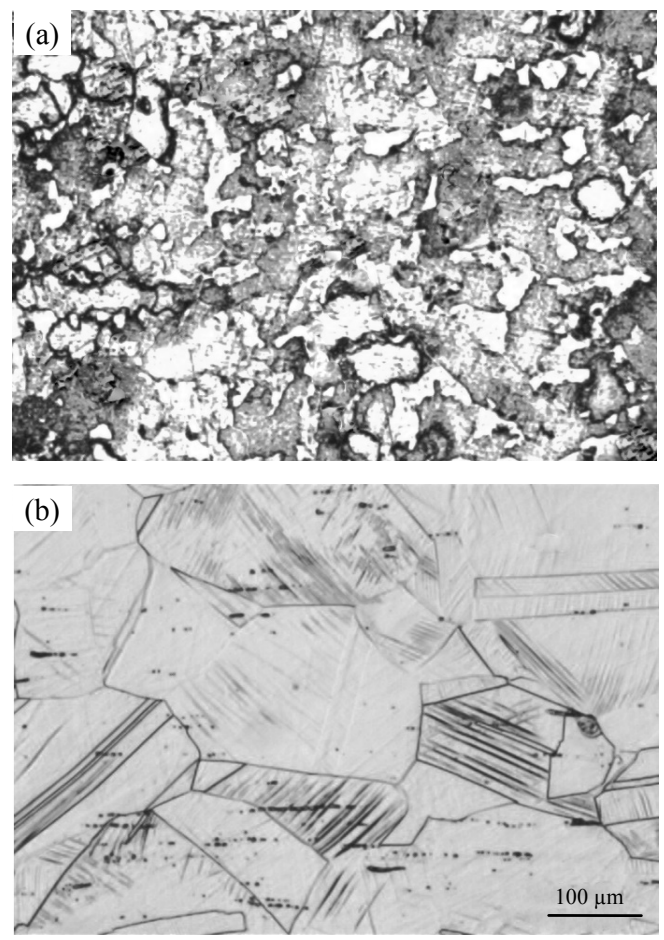

Fig. 5 Microstructures of the base materials (a) carbon steel and (b) stainless steel
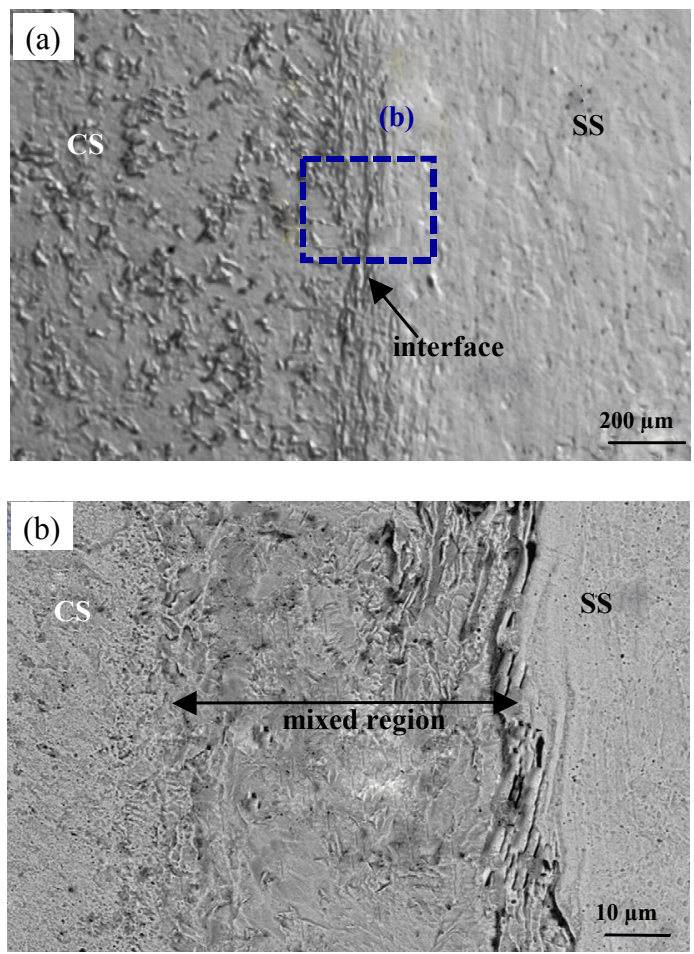

Fig. 6 Microstructures of the joints showing weld interface with the several widths of mixed region (a) optical microstructures and enlarged view of selected area of (b) SEM microstructure

region to the SS matrix showed a ragged region with the presence of multi sublayers. This is because of the

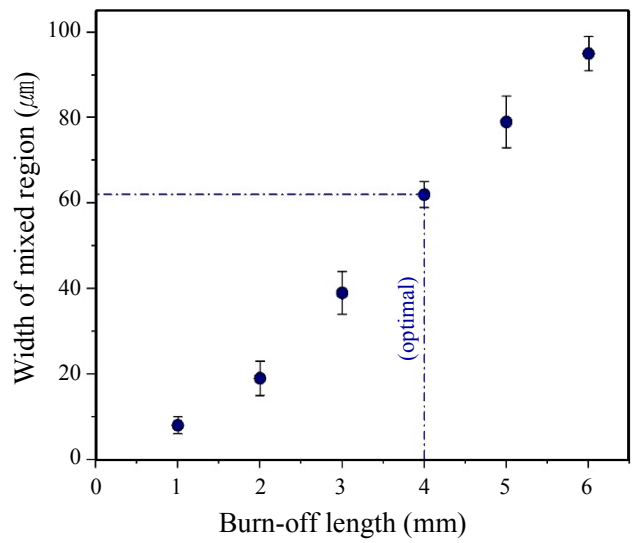

Fig. 7 Effect of burn-off length on the formation of mixed region at weld interface

higher hardenability and lower plasticity nature of the austenitic stainless steel even at high temperatures. It is also observed that, these variations are changing with the increasing of burn-off length.

Fig. 7 represents the increasing of width of intermixing region with the increasing of burn-off length. The optimal value of $4 \mathrm{~mm}$ burn-off length is determined based on the highest strength of the joints. It is identified that the width of mixed region is about $62 \mu \mathrm{m}$ for the optimized welding condition. The width of the mixed region beyond this value resulted in reduction of strength of the joints. It is identified from the microstructural observations that the changes in metallurgical properties of the joints are determined by the effect of burn-off length. These metallurgical changes of the welds between two dissimilar properties of the different materials of soft (SAE 1045) and hard (AISI 316L) materials with different chemical compositions show relation with the formation of mechanical properties. Fig. 7 shows the correlation between metallurgical changes in the joint interface with the formation of intermixing regions at different burn-off length rates. The details of the effect of intermixing region (metallurgical changes due to burn-off length) on the mechanical properties are given in next section. The width of mixed regions mainly consists of hard and soft sublayers, which are formed by the mixing of two substrates showed much influence on the mechanical properties of the joints. The presence of hard and soft sublayers in the width of intermixed region which are formed beyond the optimal value acts as a failure sites, thus reduction in strength of the joints. In order to confirm the intermixing region effect on joint properties, EBSD analysis has been carried out to study the texture evaluation and the formation of grains. Fig. 8 demonstrates the intermixed region of image quality and unique grain mapping analysis. It is clearly seen that the formation of hard and soft layers in mixed re- 

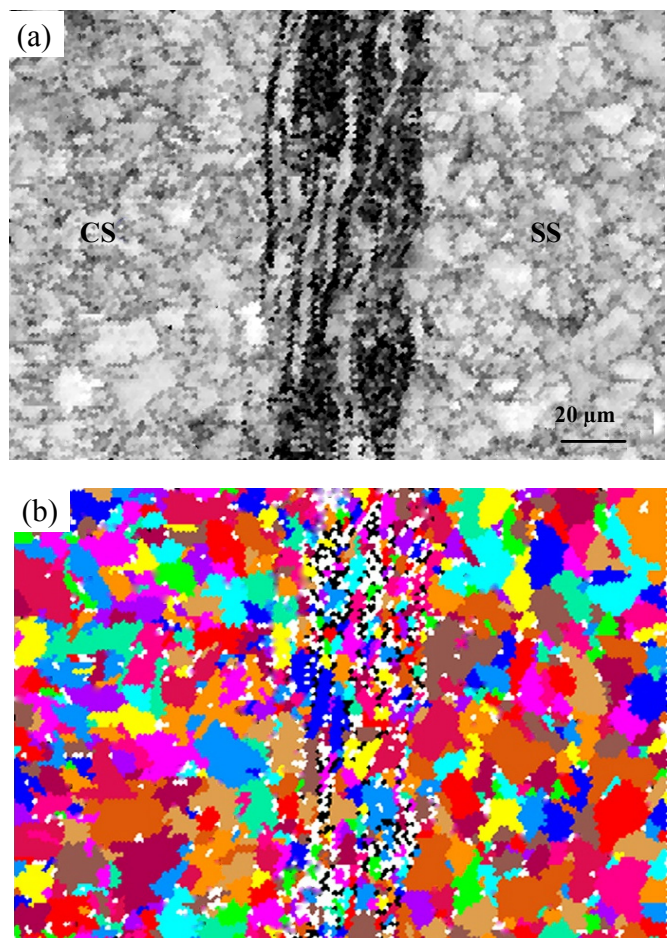

Fig. 8 EBSD analysis of the joint interface to determine the change of gran size and its distribution with burn-off length (a) gray scale image quality map and (b) grain boundaries with unique grain colour map

gion, which are resembles as white and dark regions in Fig. 8(a). Fig. 8(b) exhibits the evidence for the formation of fine grains in the mixed region and DRX region at the weld interface due to severe plastic deformation at high temperatures. It is also observed that the size of the grains of hard and soft layers distributed differently with the fine and large grains respectively. It is determined that the average grain size of DRX regions adjacent to the joint interface is about $14 \mu \mathrm{m}$ on CS side and $14.8 \mu \mathrm{m}$ on SS side. The average grain size of the CS and SS base metals (base metal microstructures are shown in Fig. 5) is about $36 \mu \mathrm{m}$ and $30 \mu \mathrm{m}$, respectively. Whereas, grain size of the mixed region is observed to below $12 \mu \mathrm{m}$, which is finer than the base metal and DRX regions. The average grain size of DRX region on CS and SS side is almost same on both sides of the interface, is owing to the formation of refined grain structure in the DRX zone. The refined grain structure at the joint interface observed to be resulted in enhancing of mechanical properties ${ }^{29-32)}$.

\subsection{Mechanical Properties}

In order to evaluate the quality and integrity of the joints mechanical properties are evaluated using microhardness and tensile tests. Vicker's microhardness values were obtained from the nano indention tester which is conducted on across the cross section of the joints. The maximum hardness of the joints obtained at joint interface where the hard and soft regions are existed in the mixed zone. The hardness values of both the layers are higher than the base metal and DRX zones. The nano indentation impressions (diagonal shape on the microstructure) on the mixed layers are illustrated in Fig. 9. To avoid the effect of strains induced by indenter for another layer of hardness value taken from the three times above the indentation in Y-axis direction. The hardness distributions of weld zones (expect mixed region) were determined in horizontal $\mathrm{X}$-axis direction (see Fig. 9 and 10). The hardness distribution varying within the mixed region from $362 \mathrm{Hv}$ to $286 \mathrm{Hv}$, this is due to the formation of hard and soft regions (see Fig. 8a and 9). Fig. 10 represents the variations in hardness distribution along the interface of welded joint with different zones. It is observed that the hardness of TMAZ and DRX regions are also showed higher hardness than the base metal. The changes in the grain structure due to severe plastic deformation during friction welding resulted in the increasing of hardness values. As mentioned in earlier section about the DRX region with the fine equi-axed grains, the hardness distribution plot is also confirmed as an evident and makes the relation between metallurgical changes to the mechanical properties. The strength of the joints were evaluated for the joints
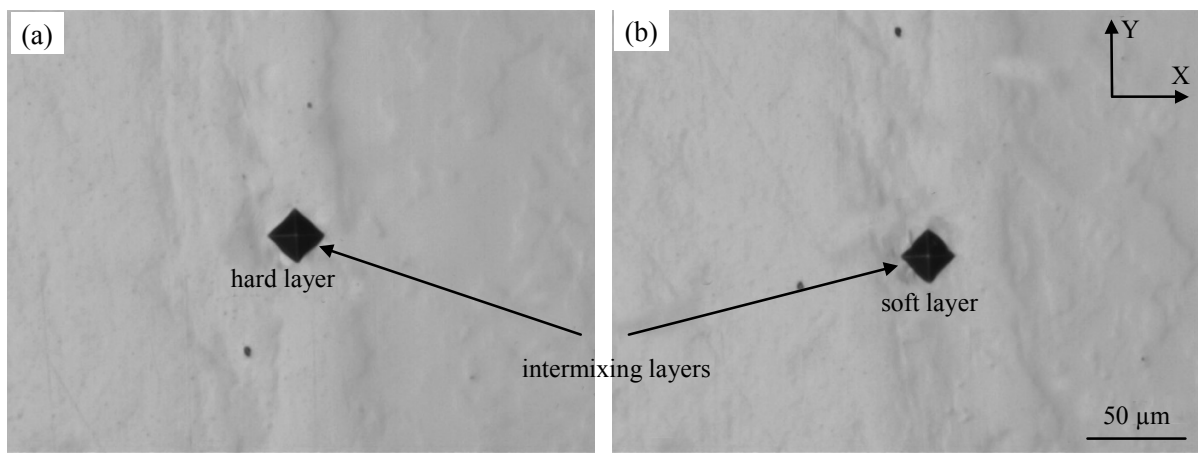

Fig. 9 Nano indentations on the intermixing layers (a) hard layer and (b) soft layer 


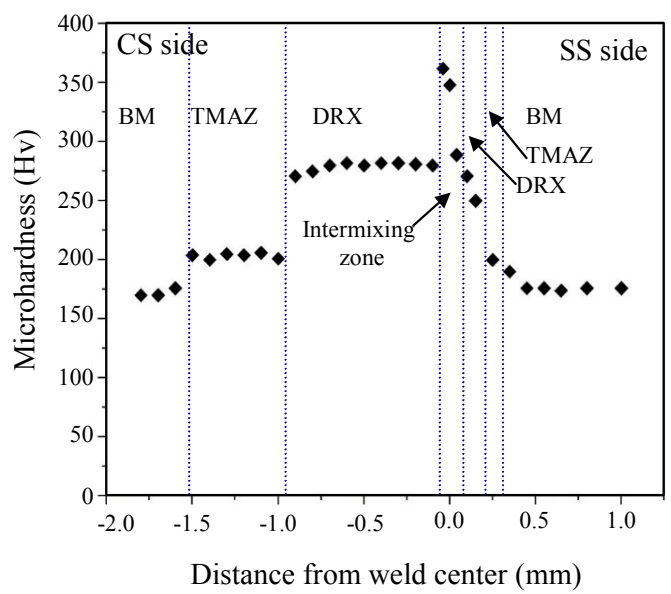

Fig. 10 Microhardness distribution across the joint interface and other zones

produced at different burn-off lengths using tensile test. As revealed in microstructural and EBSD analysis, the refined grain structure in the interface and DRX zone, are also confirmed by the microhardness distributions that the hardness of the DRX zone is higher than the base metal hardness. It is observed that the strength of joints gradually increased with increasing of burn-off length upto the optimum level, and starts to decrease after reaching its optimum value of $4 \mathrm{~mm}$ bun-off length. Fig. 11 presents the tensile strength of the joints with different burn-off lengths, maximum strength of $709 \mathrm{MPa}$ obtained at the burn-off length of $4 \mathrm{~mm}$. It is also revealed that, strength of the joints are starting to decrease with further increasing of burn-off length. The fracture occurred in the base metal near to the weld zone for the joints tested at $4 \mathrm{~mm}$ burn-off length. Whereas, the joints produced at other burn-off length values were resulted in the occurrence of fracture in weld zone. The fracture initiated at side surface of the joints and propagated towards the centre of the weld zone. The fracture morphologies and crack direction are

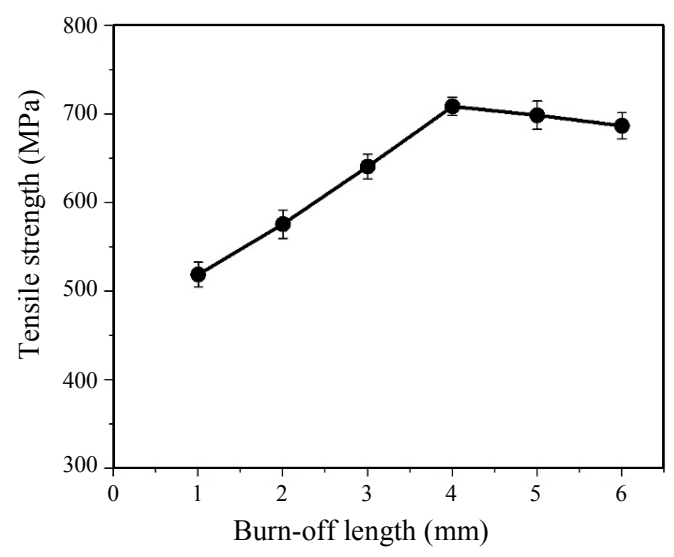

Fig. 11 Tensile strength of the joints with different burnoff length discussed in fractography section. As discussed earlier, microstructural changes with the formation of mixed layers in the joint interface could be one of the reason for reduction in joint strength ${ }^{33-38)}$. The correlated values of width of mixed region to the tensile strength and width of mixed region to the burn-off length confirms the effect burn-off length on the joint properties. The correlation plot between burn-off length and tensile strength indicates the effect of welding parameter such as burn- off length on strength of the joints. It is a fact that many studies were reported only the influence of welding conditions on the mechanical properties of the joints. It is worth to notice that the reasons behind this with proper evidences is demanded to complete understanding of the joint characteristics. The present study intend to find the evidences for understanding the relation between welding parameters and joint strength with the characterization of metallurgical properties. The formation of metallurgical properties also decide the strength of the joints. Whereas these metallurgical properties are mainly controlled by the material chemistry and welding parameters. Therefore, the effect of burnoff length on width of the intermixing zone (shown in Fig. 7) and tensile strength (shown in Fig. 11) are evaluated. The joints strength under cyclic loads were evaluated by using fatigue test as per the standard (see Fig. 1). The fatigue tests were conducted using a sinusoidal load of frequency $20 \mathrm{~Hz}$ and load ratio $\mathrm{R}=-1$, considering as fatigue strength, the complete specimens fracture at stress amplitude of $235 \mathrm{MPa}$ and $1 \times 10^{6}$ load cycles. The microstructural and mechanical properties of the joints were suggesting that the optimum value of burn-off length could be about $4 \mathrm{~mm}$ for this combination of welds. The fracture surfaces of the tensile and fatigue tests were characterised with the SEM to investigate the failure modes and nature of failure, are depicted in Fig. 12. Fig. 12 (a) and (b), indicates the fracture initiation zones and crack directions of the tensile and fatigue tested samples, respectively. It is observed that, fracture initiation for the tensile tested samples occurred at centre of the weld zone which is indicated in the Fig. 12 (a), and propagates towards to side surface of the specimen. Whereas, the fracture initiation for the fatigue tested samples occurred at side surface of the specimen and crack propagated towards centre region of the weld zone (see Fig. 12b). The fracture morphology of the tensile and fatigue tested samples shows the ductile nature of the failures with the presence of small dimples on the surfaces. The further analysis of fracture surfaces were revealed that the presence of shearing edges on tensile fracture surfaces, where the difference in visibility of the SEM image as shown in Fig. 12(c). The presence of shearing edges on fracture surfaces are due to the formation of mixed hard 

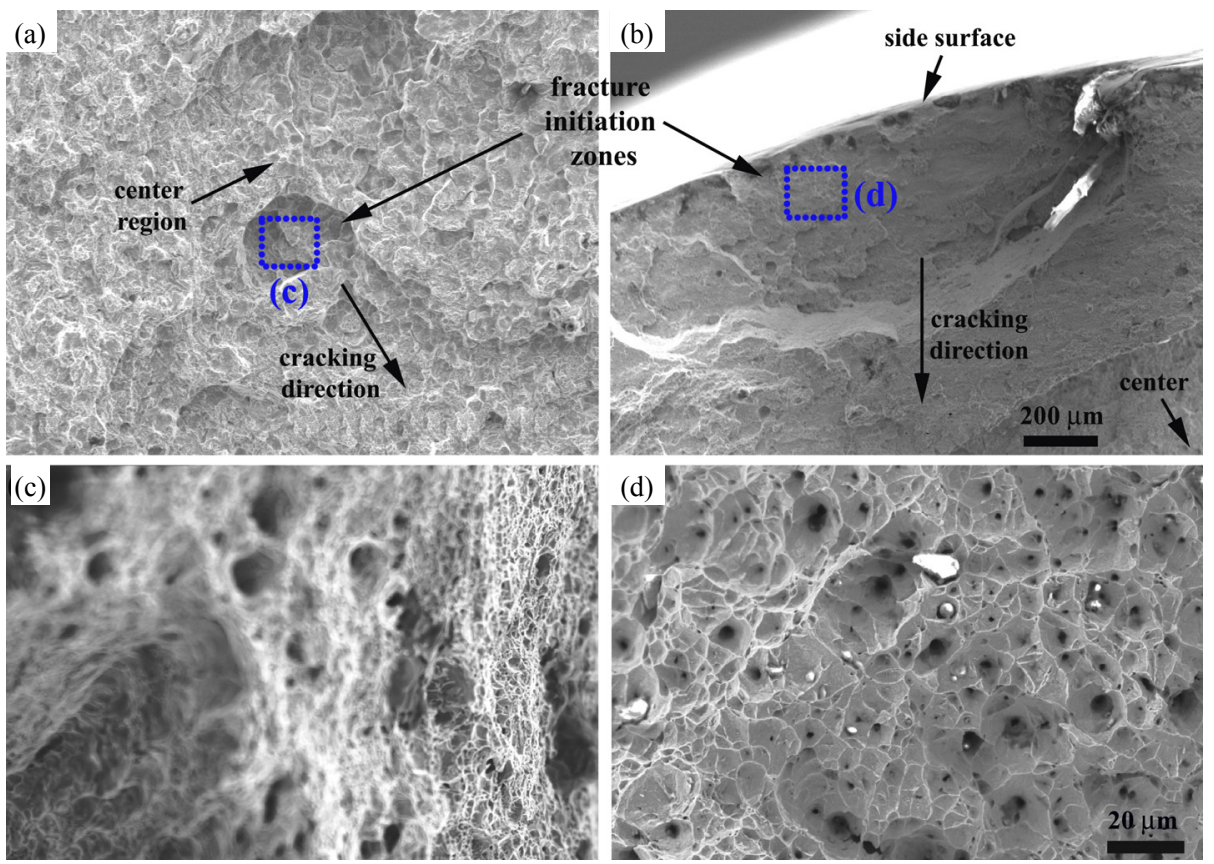

Fig. 12 SEM microstructures illustrates the fracture surface morphology of (a) and (c) tensile test and, (b) and (d) fatigue test

and soft sublayers in the intermixed zone. Whereas, the significance of presence of shearing edges in the fatigue tested samples is comparatively low and, are difficult to identify from the fracture morphology surfaces (see Fig. 12d). The effect of burn-off length in friction welding is one of the significant welding parameter where to determine the pro- perties of the joints. The material loss in friction welding is one of the concerning issue for the final components, the present study contributes the significance of material loss in welds for a required strengths. The changes in metallurgical and mechanical properties of joints were evaluated under different burn-off lengths and determined the optimum value of $4 \mathrm{~mm}$ burn-off lengths for the friction welding combination of carbon steel to stainless steel to attain the quality joints.

\section{Conclusions}

The dissimilar combinations of carbon steel to stainless steel are successfully joined using friction welding process. From this investigation, following important conclusions are derived.

1) Tensile strength of friction welded dissimilar joints of CS and SS is maximum of $709 \mathrm{MPa}$ at burn-off length of $4 \mathrm{~mm}$.

2) The maximum hardness values are identified at weld interface and its values varied from $362 \mathrm{Hv}$ to $286 \mathrm{Hv}$.

3) The width of intermixed region for the joints obtained at $4 \mathrm{~mm}$ burn-off length is about $62 \mu \mathrm{m}$ which is optimized based on the strength of the joints.
4) EBSD analysis confirms the presence of refined fine grains and sublayers in intermixed zone with the grain size is about $12 \mu \mathrm{m}$, which is finer than the other zones.

5) The strength of friction welds and width of intermixed zone both are increases with increasing of burnoff length upto $4 \mathrm{~mm}$.

\section{Acknowledgments}

This research was supported by Kyungsung University research grants in 2018.

ORCID: Muralimohan Cheepu: http://orcid.org/0000-0002-8282-1237 ORCID: Woo-Seong Che: http://orcid.org/0000-0003-3975-6369

\section{References}

1. Peng Li, Jinglong Li, Muhammad Salman, Li Liang, Jiangtao Xiong and Fusheng Zhang, Effect of friction time on mechanical and metallurgical properties of continuous drive friction welded Ti6A14V/SUS321 joints, Materials and Design, 56 (2014), 649-656

https://doi.org/10.1016/j.matdes.2013.11.065

2. C. H. Muralimohan, M. Ashfaq, Rouholah Ashiri, V. Muthupandi and K. Sivaprasad, Analysis and characterization of the role of $\mathrm{Ni}$ interlayer in the friction welding of titanium and 304 austenitic stainless steel, $\mathrm{Me}$ tallurgical and Materials Transactions A, 47(1) (2016), 347-359

https://doi.org/10.1007/s11661-015-3210-z 
3. D. Ananthapadmanaban, V. Seshagiri Rao, Nikhil Abraham, K. Prasad Rao, A study of mechanical properties of friction welded mild steel to stainless steel joints, Materials and Design, 30(7) (2009), 2642-2646

https://doi.org/10.1016/j.matdes.2008.10.030

4. Muralimohan Cheepu, V. Muthupandi and Woo Seong Che, Improving mechanical properties of dissimilar material friction welds, Applied Mechanics and Materials, 877 (2018), 157-162

https://doi.org/10.4028/www.scientific.net/AMM.877.157

5. S. M. Shushan, E. A. Charles and J. Congleton, The environment assisted cracking of diffusion bonded stainless to carbon steel joints in an aqueous chloride solution, Corrosion Science, 38(5) (1996), 673-686 https://doi.org/10.1016/0010-938X(96)00158-8

6. R. L. Klueh, J. F. King and J. L. Griffith, A simple test for dissimilar-metal welds, Welding Research Supplement 1 (1983), 154-159

7. C. H. Muralimohan, S. Haribabu, Y. Hariprasada Reddy, V. Muthupandi and K. Sivaprasad, Evaluation of microstructures and mechanical properties of dissimilar materials by friction welding, Procedia Materials Science, 5 (2014), 1107-1113 https://doi.org/10.1016/j.mspro.2014.07.404

8. Murali Mohan Cheepu, V. Muthupandi and S. Loganathan, Friction welding of titanium to 304 stainless steel with electroplated nickel interlayer, Materials Science Forum 710 (2012), 620-625

https://doi.org/10.4028/www.scientific.net/MSF.710.620

9. C. H. Muralimohan, V. Muthupandi and K. Sivaprasad, The influence of aluminium intermediate layer in dissimilar friction welds, International Journal of Materials Research, 105(4) (2014), 350-357

https://doi.org/10.3139/146.111031

10. A. N. Dobrovidov, Selection of optimum conditions for the friction welding of high speed steel 45, Welding Production, 22(3) (1975), 22-26

11. Mumin Sahin, Evaluation of the joint-interface properties of austenitic-stainless steels (AISI 304) joined by friction welding, Materials and Design, 28 (2007), 22442250

https://doi.org/10.1016/j.matdes.2006.05.031

12. S. D. Meshram, T. Mohandas and G. Madhusudhan Reddy, Friction welding of dissimilar pure metals, Journal of Materials Processing Technology, 184 (1-3) (2007), 330337 https://doi.org/10.1016/j.jmatprotec.2006.11.123

13. C. H. Muralimohan, V. Muthupandi and K Sivaprasad, Properties of friction welding titanium-stainless steel joints with a nickel interlayer, Procedia Materials Science, 5 (2014), 1120-1129

https://doi.org/10.1016/j.mspro.2014.07.406

14. Li Peng, Dong Honggang, Xia Yueqing, Hao Xiaohu, Wang Shuai, Pan Longwei and Zhou Jun. Inhomogeneous interface structure and mechanical properties of rotary friction welded TC4 titanium alloy/316L stainless steel joints. Journal of Manufacturing Processes, 33 (2018), 54-63

https://doi.org/10.1016/j.jmapro.2018.05.001

15. Muralimohan Cheepu, M. Ashfaq and V. Muthupandi, A new approach for using interlayer and analysis of the friction welding of titanium to stainless steel, Transactions of the Indian Institute of Metals, 70(10) 2591-2600 https://doi.org/10.1007/s12666-017-1114-X

16. W. Y. Li, T. J. Ma, S. Q. Yang, Q. Z. Xu, Y. Zhang, J. L. $\mathrm{Li}$ and H. L. Liao, Effect of friction time on flash shape and axial shortening of linear friction welded 45 steel, Materials Letters, 62(2) (2008), 293-296 https://doi.org/10.1016/j.matlet.2007.05.037

17. Masaaki Kimura, Yosuke Ohtsuka, Masahiro Kusaka, Kenji Seo and Akiyoshi Fuji, Effect of friction time and friction pressure on tensile strength of welded joint for medium and high carbon steels by low heat input friction welding method, Journal of the Japan Welding Society, 23(4) (2005), 577-586 https://doi.org/10.2207/qjjws.23.577

18. N. Arivazhagan, Surendra Singh, Satya Prakash and G. M. Reddy, Investigation on AISI 304 austenitic stainless steel to AISI 4140 low alloy steel dissimilar joints by gas tungsten arc, electron beam and friction welding, Materials and Design, 32 (2011), 3036-3050 https://doi.org/10.1016/j.matdes.2011.01.037

19. Se-Gyoung Lee, Byung-Hoon Min, Su-Hyun Choi, DoKi Shim and Taeg-Ki Min, A study on mechanical properties and friction weldability of SKH51 and SM45C, Journal of KWJS, 25(5) (2007), 53-58

20. R. Paventhan, P. R. Lakshminarayanan and V. Balasubramanian, Optimization of friction welding process parameters for joining carbon steel and stainless steel, Journal of Iron and Steel Research, International, 19(1) (2012), 66-71 https://doi.org/10.1016/S1006-706X(12)60049-1

21. P. Sathiya, S. Aravindan and A. Noorul Haq, Mechanical and metallurgical properties of friction welded AISI 304 austenitic stainless steel, International Journal of Advanced Manufacturing Technology, 26 (2005), 505-511 https://doi.org/10.1007/s00170-004-2018-6

22. D. G. Lee, K. C. Jang, J. M. Kuk and I. S. Kim, Fatigue properties of inertia dissimilar friction-welded stainless steels, Journal of Materials Processing Technology, 155156 (2004), 1402-1407 https://doi.org/10.1016/j.jmatprotec.2004.04.400

23. N. Ozdemir, Investigation of mechanical properties of friction welded joints between AISI 304 L and AISI 4340 steel as a function of rotational speed, Materials Letters, 59 (2005), 2504-2509 https://doi.org/10.1016/j.matlet.2005.03.034

24. Sangathoti Haribabu, Muralimohan Cheepu, Lakshmipathi Tammineni, Naresh Kumar Gurasala, Venkateswarlu Devuri and Venkata Charan Kantumuchu, Dissimilar 
friction welding of AISI 304 austenitic stainless steel and AISI D3 tool steel: mechanical properties and microstructural characterization, In: Lakshminarayanan A., Idapalapati S., Vasudevan M. (eds) Advances in Materials and Metallurgy. Lecture Notes in Mechanical Engineering, (2019), 271-281 https://doi.org/10.1007/978-981-13-1780-4_27

25. C. H. Muralimohan and V. Muthupandi, Friction welding of type 304 stainless steel to CP titanium using nickel interlayer, Advanced Materials Research, 794 (2013), 351-357 https://doi.org/10.4028/www.scientific.net/AMR.794.351

26. I. Nikitin and M. Besel, Correlation between residual stress and plastic strain amplitude during low cycle fatigue of mechanically surface treated austenitic stainless steel AISI 304 and ferritic-pearlitic steel SAE 1045, Materials Science and Engineering: A, 491(1-2) (2008), 297-303 https://doi.org/10.1016/j.msea.2008.03.034

27. J. Outinen and P. Mäkeläinen, Mechanical properties of structural steel at elevated temperatures and after cooling down, Second International Workshop, Structures in Fire, Christchurch, (2002), 273-290 https://doi.org/10.1002/fam.849

28. R. S. Mishra, Z. Y. Ma, Friction stir welding and processing, Materials Science and Engineering R, 50 (2005), $1-78$ https://doi.org/10.1016/j.mser.2005.07.001

29. P. Sathiya, S. Aravindan and A. Noorul Haq, Op- timization for friction welding parameters with multiple performance characteristics, International Journal of Mechanics and Materials in Design, 3(4) (2006), 309-318 https://doi.org/10.1007/s10999-007-9037-z

30. S. P. Murugan, M. Cheepu, V. Vijayan, C. Ji, and Y.-D. Park, The resistance spot weldability of a stainless seel/ aluminium/low carbon steel 3-ply clad sheet. Journal of Welding and Joining, 36(1) (2017), 25-33 https://doi.org/10.5781/JWJ.2018.36.1.3

31 J. H. Shin, and K.-S. Bang, Study on diffusion bonding characteristics of austenitic stainless steels. Journal of Welding and Joining, 36(5) (2018) 81-87 https://doi.org/10.5781/JWJ2018.36.5.11
32. M. Cheepu, V. Muthupandi, D. Venkateswarlu, B. Srinivas, W. S. Che, Interfacial microstructures and characterization of the titanium-stainless steel friction welds using interlayer technique. In: Parinov I., Chang SH., Gupta V. (eds) Advanced Materials. PHENMA 2017. Springer Proceedings in Physics, vol 207. Springer, Cham (2018) 267-283 http://doi.org/10.1007/978-3-319-78919-4_21

33. D. Krishnaja, M. Cheepu, D. Venkateswarlu, A review of research progress on dissimilar laser weld-brazing of automotive applications. IOP Conference Series: Materials Science Engineering 330 (1), (2018) 012073 https://doi.org/10.1088/1757-899X/330/1/012073

34. M. Cheepu, B. Srinivas, N. Abhishek, T. Ramachandraiah, S. Karna, D. Venkateswarlu, S. Alapati, W. S. Che, Dissimilar joining of stainless steel and 5083 aluminum alloy sheets by gas tungsten arc welding-brazing process. IOP Conference Series: Materials Science and Engineering, 330(1) (2018) 012048 https://doi.org/10.1088/1757-899X/330/1/012048

35. J. Moon, H. Y. Ha, T. H. Lee, Microstructure evolution and corrosion behavior in the welds of high interstitial FeCrMnNC austenitic stainless steels. Journal of Welding and Joining, 35(4) (2017), 51-57 http://doi.org/10.5781/JWJ.2017.35.4.8

36. M. Cheepu, V. Muthupandi, B. Srinivas, K. Sivaprasad, Development of a friction welded bimetallic joints between titanium and 304 austenitic stainless steel. TechnoSocietal 2016, International Conference on Advanced Technologies for Societal Applications. Springer, Cham. (2016) (709-717) http://doi.org/10.1007/978-3-319-53556-2_73

37. C. H. Muralimohan, S. Haribabu, Y. H. Reddy, V. Muthupandi, K. Sivaprasad, Joining of AISI 1040 steel to 6082-T6 aluminium alloy by friction welding. Journal of Advances in Mechanical Engineering and Science, 1(1) (2015) 57-64 http://dx.doi.org/10.18831/james.in/2015011006

38. M. Joonoh, J. Lee, C.-H. Lee, T.-H. Lee, S.-J. Jung, S.-H. Jeong, H.-U. U. Hong, Microstructure and mechanical properties of the welds of reduced-activation ferritic / martensitic steels. Journal of Welding and Joining 36 (1) (2018), 18-24 https://doi.org/10.5781/JWJ.2018.36.1.2 